\title{
The Relationship of Identity Styles and Attitude toward Delinquency with Delinquent Behavior of Adolescents
}

\author{
Abbas Habibzadeh ${ }^{*}$, Mahnaz Khazaili², Aliakbar Assarnia ${ }^{2}$ \\ 1. Department of Education, Faculty of Humanities and Letters, University of Qom, Qom, Iran. \\ 2. Department of Psychology, Faculty of Humanities, Qom Branch, Islamic Azad University, Qom, Iran.
}

dtation: Habibzadeh, A., Khazaili, M., \& Assarnia, A. A. (2016). The Relationship of Identity Styles and Attitude toward Delinquency with Delinquent Behavior of Adolescents. Journal of Practice in Clinical Psychology, 4(3), 145-150. http://dx.crossref.org/10.15412/J.JPCP.06040301

of: http://dx.crossref.org/10.15412/J.JPCP.06040301

\section{Article info:}

Received: 11 Jan. 2016

Accepted: 14 May 2016

Keywords:

Identity style, Attitude toward delinquency, Delinquent behavior

\section{ABSTRACT}

Objective: The present research aimed to study the relationship of identity styles and attitude toward delinquency with delinquent behavior of adolescents.

Methods: The present research is a cross sectional study. Data collection tools were Berzonsky's identity style inventory, attitude toward delinquent behaviors questionnaire, and interviews, which were analyzed through simultaneous regression analysis using SPSS software. Study sample consisted of all 150 male adolescents who were detained in Tehran's Center for Correction and Rehabilitation for committing delinquency/crime.

Results: Based on the obtained results, informational, normative, diffuse/avoidant, and commitment identity styles had significant associations with delinquency and positive and negative attitude toward delinquent behavior. In other words, identity styles and attitude toward delinquent behavior explained $57 \%$ of the changes in adolescents' delinquent behavior $(\mathrm{P}<0.001)$.

Conclusion: Given the importance of family and social models in the formation of identity styles as well as positive and negative attitudes toward delinquency, it is necessary to offer individual and group courses of educating families and adolescents to control and prevent delinquent behavior as well as providing suitable models for adolescents to gain proper identities.

\section{Introduction}

$\mathbf{D}$

elinquent behavior is a complex and multifaceted process affected by the environmental factors and individual characteristics. Anti-social behavior and delinquency include a wide range of behavioral disorders such as aggression, violence, rubbery, escaping from school and home, lying, and carrying gun which violate law and the rights of others (American Psychiatric Association, 2000).

Delinquency is defined as a legal issue and delinquent behaviors refer to a set of behaviors that violate the laws and norms and harm the society and other individuals. In general, such activities as murder, theft, fighting, vandalism, fraud, rape, looting, violence, and arson are consid-

\footnotetext{
* Corresponding Author:

Abbas Habibzadeh, PhD

Address: Department of Education, Faculty of Humanities and Letters, University of Qom, Qom, Iran.

Tel: +98 (912) 6529403

E-mail: habibzade2008@yahoo.com
} 
ered as delinquent behaviors and almost all communities agree on its definition (Navah \& Kouhpaie, 2012).

To explain the etiology of aggression and aggressive crimes, different theorists refer to a collection of biological, psychological, social, and cultural factors (Khademi, 2010). Genetic studies have provided significant evidence about anti-social behavior and identified genes related to anti-social behavior. However, the role of genetic factors is manifested in interaction with environmental factors (Khademi, 2010). Neurological research has revealed structural and functional defects in the frontal, temporal and subcortical areas of antisocial individuals as well as deficiencies in their verbal, spatial, and operational abilities.

Meanwhile, social psychologists emphasize the role of individual and environmental factors in the emergence of aggressive and delinquent behavior and by using the social learning theory and social cognition theory, accurately explaining crime and delinquency (Green, Oliver, Crawley, Penn, \& Silverstein, 2005). Social learning is creating, maintaining, and modifying the behavior of an individual within the community he or she lives. Therefore, a person who lives in a disorganized society has the potential to learn many types of crimes and deviances (Zare, 2013). In fact, the social learning theory emphasizes the interplay between behavior and environment and focuses on behavior patterns that the individual adapts to cope with the environment; patterns which are acquired through direct experience, environment's responses to the individual or observing the responses of others (Bayat, Sherafati, \& Abdi, 2008).

According to experts, an adolescent seeks for an independent identity, which is one of the important needs of human beings, especially at this age. Many factors affect a person's identity, such as family, educational institutions, social change, social groups, cultural elements, mass media, and the roles a person has played or will play (Pouryousefi, Tayefeh, \& Aghapour, 2009). If gaining identity during adolescence is delayed for whatever reason, then in his youth, the adolescent will try to acquire a new identity to determine the framework, purpose, and way of his or her life. At this time, apart from few exceptions, most people identify with other people through assimilation and social learning so that to enjoy a sense of security. In studies of human personality, identity is a fundamental and innate aspect, which links a person to his or her past and gives his or her life a sense of continuity and integrity. In other words, identity is the individual's subjective perception of himself or herself and has different dimensions such as sexual identity, group identity, ethnic identity, etc (as quoted by Esmail Kalaie, 2010).

The latest theory about identity, which serves as the theoretical basis of this research is Berzonsky's identity style theory. This theory introduces the cognitive-social model which deals with the differences between people in using social-cognitive process, decision making, problem solving, dealing with challenges, doing assignments, and enjoying general cognitive health. According to this model, Berzonsky (1989) identified 3 identity styles: informational, normative, and diffuse/avoidant (Berzonsky \& Kuk, 2005).

Separate studies have been conducted in connection with the above variable; for example, Almasi (2007) has conducted a comparative study of social factors associated with the tendency toward delinquent behavior among male high school students, living in the suburban and nonsuburban areas of Ilam City, Iran. Based on the results of aforementioned study, there is a strong and inverse correlation between attachment to school and tendency toward delinquent behavior among students. Also, there is a direct correlation between the number of delinquent friends and tendency toward delinquent behavior. In another study, more than $30.0 \%$ of the subjects were still in search of identity up to the age of 24 . Another research suggests that the formation of personal identity may even be an ongoing process that occurs throughout life (Schultz \& Schultz, 2005).

In a research, Hyun lee (2009) studied the effect of parental supervision on delinquent behavior. The findings suggest that parental supervision and their presence in adolescents' everyday life can reduce the risk of delinquent behavior among them. Also, variables that are correlated with the structure of the family and peer groups are significant predictors of delinquency. In a research entitled "A Comparison of Parenting Styles and Identity Styles in Normal and Delinquent Adolescents", Azizi and Tarkhan (2014) showed that there is a significant difference between the identity styles of normal and delinquent adolescents, also identity styles are one of the fundamental factors in delinquent behavior of children and adolescents. In a research entitled "The Relationship between Identity Styles, Identity Commitment and Gender and Social Compatibility", Mikaeili (2008) concluded that identity styles can significantly explain and predict all components of social compatibility.

Adams, Munro, Munro, Doherty-Poirer, Ed wards (2005), in a study of identity styles and behavioral problems, observed that individuals with diffuse/avoidant 
identity style exhibit more behavioral problems such as delinquency or behavioral disorders than those with other two identity styles. In their research entitled "The Relationship between Identity Styles and Social Compatibility in Addicts", Julia Muller and Christiane Schwieren (2012; as quoted by Yavari, 2013) concluded that identity styles are predictors of social compatibility in addicts.

Considering the above-mentioned issues, the necessity of studying the relationship of identity styles and attitude toward delinquency with delinquent behavior is felt. In addition, the social and economic costs of delinquency have made it the main priority of researchers, specialists, and officials to identify its causes among adolescents (Cohen \& Piquer, 2009). In this regard, the aim of the present research was to study the relationship of identity styles and attitude toward delinquency with delinquent behavior of adolescents.

\section{Methods}

The research method is cross sectional. Statistical population comprised of all male adolescents who commit delinquency/crime. Study sample consisted of all 150 male adolescents who were detained in Tehran's Center for Correction and Rehabilitation for committing delinquency/crime during 2015-2016. Due to limitations of the research population and the type of the study, all of them were studied as the sample population. To analyze the data, SPSS 20 was used to perform simultaneous regression analysis. At first, the permission for conducting the research was obtained in coordination with the authorities of the Center for Correction and Rehabilitation. Then, the subjects' informed consents were taken to complete the questionnaire.

Identity style inventory was developed by Berzonsky in 1989 to evaluate the orientation of individuals' identity. It was revised in 1992. This test is a self-report tool, including 4 subscales: 3 of them are identity styles and 1 is related to commitment. Subscales of identity style inventory are as follows:

Informational; People who score high in this scale only make a decision after collecting information, assessing potential alternatives, and processing the information.

Normative; People who score high in this scale follow the rules and norms set by their parents, spouses or friends without investigation.

Diffuse/Avoidant; people with a diffuse/avoidant orientation delay decision making as long as possible.
Commitment; This subscale shows to what extent the subject feels commitment to religion, politics and his field of expertise.

Using a 5-point Likert-type scale (0 stands for never and 5 stands for very often), the subject must specify to what extent each of the statements reflect his or her personality traits. Regarding the reliability of this questionnaire, its external reliability was obtained by using the test-retest method over a period of 2 weeks in which informational orientation subscale was 0.87 , normative orientation 0.87 , diffuse/avoidant orientation 0.83 , and commitment subscale 0.89 . In Iran, reliability of this scale for students has a special form for the students, which has been normalized on high school students and is very similar to the main questionnaire indicating its acceptable reliability.

Attitude toward delinquent behavior questionnaire was developed by Vahid Fazli in 2010 to measure the attitude toward delinquent behavior of adolescents aged 15-18 years. It includes 28 items and is scored based on 4-point Likert-type scale. This tool is used to determine positive/ negative attitude toward delinquent behavior. In a pilot survey, the questionnaire w used for 200 adolescent students aged 15-18 years at state-run schools in Tehran. Using the Cronbach $\alpha$, the reliability of both positive attitude toward delinquent behavior and negative attitude toward delinquent behavior was obtained to be 0.71 (Sa’adat \& Khodayari Saghavaz, 2012).

\section{Results}

The obtained results showed that the mean age of delinquent adolescents was 15.85 years with the standard deviation of 1.52 years and most adolescent delinquents were primary $(51.3 \%)$ or high school $(36 \%)$ students. Also, out of the total number of the research sample members, $53.3 \%, 40.7 \%$, and $6 \%$ were in Center for Correction and Rehabilitation for 1, 2, and 3 years, respectively. In addition, $62.7 \%$ of the subjects had family members and first-degree relatives with imprisonment records. Based on Table 1, the highest mean among identity styles was that of normative identity style with the mean of 34.07. Also, most of the delinquent adolescents had a positive attitude toward delinquent behavior (with the mean of 51.56). Table 2 shows that all identity styles, except for normative orientation, have a negative and significant correlation with delinquent behavior. Additionally, positive attitude has a positive and significant correlation with delinquent behavior and negative attitude has a negative correlation with delinquent behavior. Simultaneous regression analysis was performed to 
Table 1. Mean and Standard deviation of research variables.

\begin{tabular}{cccc}
\hline Variable & Components & Mean & Standard deviation \\
\hline & Informational & 24.75 & 2.62 \\
Identity styles & Normative & 34.07 & 4.36 \\
& Diffuse/avoidant & 25.81 & 3.37 \\
& Commitment & 24.70 & 2.86 \\
Attitude toward delinquent & Positive attitude & 51.56 & 9.56 \\
\hline behavior & Negative attitude & 27.72 & 3.47 \\
\hline
\end{tabular}

Table 2. Results of correlation analysis of the research variables.

\begin{tabular}{ccccccccc}
\hline & Variable & $\mathbf{1}$ & $\mathbf{2}$ & $\mathbf{3}$ & $\mathbf{4}$ & $\mathbf{5}$ & $\mathbf{6}$ & $\mathbf{7}$ \\
\hline 1 & Delinquent behavior & 1 & & & & & & \\
2 & Informational identity & $-0.61^{* *}$ & 1 & & & & & \\
3 & Normative & $0.47^{* *}$ & 0.42 & 1 & & & & \\
4 & Diffuse/avoidant & $-0.49^{* *}$ & 0.31 & 0.26 & 1 & & & 1 \\
5 & Commitment & $-0.42^{* *}$ & 0.28 & 0.24 & 0.35 & 1 & & \\
6 & Positive attitude & $0.39^{* *}$ & -0.27 & -0.17 & -0.30 & 0.28 & 1 \\
7 & Negative attitude & $-0.29^{* *}$ & 0.14 & 0.30 & 0.21 & 0.17 & 0.20 & 1 \\
\hline
\end{tabular}

PRACTIEE in
CLINICAL PSYCH $\cong$ LOGY

Table 3. Results of simultaneous regression analysis of delinquent behavior, identity styles, and attitude toward delinquency.

\begin{tabular}{cccccccc}
\hline Predictor variable & SE & $\boldsymbol{\beta}$ & $\mathbf{P}$ & $\mathbf{R}$ & $\mathbf{R}^{2}$ & $\mathbf{F}$ & $\mathbf{P}$ \\
\hline Informational identity & 0.016 & -0.37 & 0.0001 & 0.75 & 0.57 & 31.87 & 0.001 \\
Normative identity & 0.018 & 0.15 & 0.01 & & & & \\
Diffuse/avoidant identity & 0.012 & -0.21 & 0.001 & & & & \\
Commitment & 0.014 & -0.12 & 0.03 & & & & \\
Positive attitude & 0.004 & 0.17 & 0.006 & & & \\
Negative attitude & 0.11 & -0.15 & 0.01 & & & \\
\hline
\end{tabular}

PRACTIEE in
CLINICAL PSYCH $\cong$ LOGY

predict delinquent behavior based on identity styles and attitude toward delinquent behavior (Table 3). A significant regression equation was found $(\mathrm{F}=31.87, \mathrm{P}<0.001)$, with a $\mathrm{R}^{2}$ of 0.57 . All identity styles and attitude toward delinquent behavior were significant predictors of delinquent behaviors of the subjects ( $\mathrm{P}<0.03$ to $\mathrm{P}<0.0001$ ).

\section{Discussion}

Delinquent behavior and delinquency are observed in any society; therefore, studying the variables related to them was one of the main reasons for conducting the present research. Based on the results, identity styles and attitude toward delinquent behavior together explain $57 \%$ of the changes in delinquent behaviors of adolescents. Informational, normative, diffuse/avoidant, and commitment identity styles as well as negative attitude toward delinquent behavior negatively explained delinquent behavior. Considering the formation of individuals' identity and the role of social learning, especially the fact that most individuals' identity is formed by their attitude and family relationships, the role of learning becomes more conspicuous.

Furthermore, based on a research conducted by Hyun, lee (2009), parental supervision and their presence in ad- 
olescents' everyday life can reduce the risk of delinquent behavior. In addition, variables which are correlated with family structure and peers group are significant predictors of the delinquency. In the present research, considering the higher score of most adolescents in normative identity style, it is concluded that these adolescents follow the rules and norms set by their parents or friends without investigation; therefore, the role of social learning becomes more conspicuous.

In line with this conclusion, lower scores in other identity styles indicate improper information processing, delay in decision making, and lack of sense of commitment. In this regard, results of the present research are consistent with the findings of Adams et al. (2005) and Mikaeili (2008) who studied the relationship of identity styles and delinquent behavior with social compatibility.

Our results also indicate that positive attitude toward delinquent behavior positively predicts delinquent behavior of adolescents and negative attitude negatively predicts delinquent behavior of adolescents. Because most delinquent adolescents had family members with criminal background, many researchers (Cassidy, 2011; Gao, Yu, \& Kin, 2013; Ekpo \& Ajake, 2013) reported that family can play a significant role in creating positive/negative attitude toward delinquency in adolescents. Modeling and learning different types of behavior in family have a significant impact on adolescents' attitude toward delinquency and crime as well as anti-social behaviors. Also, the presence of delinquent friends and unsuitable environment further reveal the role of social learning in determining the positive/negative attitude toward delinquency and delinquent behavior. In this regard, sociologists argue that delinquent behaviors and different attitudes toward delinquency emerge because of the direct impact of various behaviors in social environment and deviations in different social contexts, so that delinquency and crime are learned like the way that law-abiding behaviors are learned and generally meet a similar need (Giddens, 2006).

The main limitation of the present research is the use of self-report tool (questionnaire) and lack of cooperation of some delinquent adolescents who refused to fill in or return the questionnaires. Taking into consideration the results of the present research and the importance of identity styles and attitude toward delinquent behavior of adolescents in the process of learning and development of delinquency, it is recommended that the authorities at the correction and rehabilitation centers hold group guidance and counseling meetings for parents. At these group meetings which are held by psychologists and counseling experts, proper methods of gaining identity and suit- able coping strategies for better compatibility should be taught so that improper modeling is minimized and positive attitude toward delinquency is reduced. It is also recommended that similar research be conducted on other statistical samples.

\section{Acknowledgements}

The current research hasn't received any financial support.

\section{Conflict of Interests}

The authors declared no conflict of interests.

\section{References}

Adams, G. R., Munro, B., Munro, G., Doherty-Poirer, M., \& Edwards, J. (2005). Identity processing styles and Canadian adolescents self-reported delinquency. Identity, 5(1), 57-65.

Almasi, M. (2007). [Comparative study of the social factors related to tendency toward delinquent behavior among suburban and nonsuburban citizens of Ilam city (Persian)] (MA thesis). Shiraz: University of Shiraz.

American Psychiatric Association. (2000). Diagnostic and Statistical Manual of Mental Disorders ( $4^{\text {th }}$ ed, Text Revision) (DSMIV-TR). Washington, D.C.: American Psychiatric Association.

Bayat, B., Sherafati, J., \& Abdi, N. (2008). [Preventing Crime by Adapting a Society-based Approach (Persian)]. Tehran: Social deputy of Law Enforcement Force of Islamic Republic of Iran.

Berzonsky, M. D., \& Kuk, L. S. (2005). Identity style, psychosocial maturity, and academic performance. Personality and Individual Differences, 39(1), 235-47.

Berzonsky, M. D. (1989). Identity style: conceptualization and measurement. Journal of Adolescent Research, 4(3), 268-82.

Cassidy, T (2011). Family background and environment, psychological distress, juvenile delinquency. Psychology, 2(9), 941-47.

Cohen, M. A., \& Piquero, A. R. (2009). New evidence on the monetary value of saving a high risk youth. Journal of Quantitative Criminology, 25(1), 25-49.

Ekpo, T. E., \& Ajake, U. E. (2013). Family socio-economic status and delinquency among senior secondary school students in calabar south, cross river state, Nigeria. American Journal of Contemporary Research, 3(4), 83-88.

Gao, Y., Yu, Y., \& Kin, N. T. (2013). A study of the moderating effect of family functioning on the relationship between deviant peer affiliation and delinquency among Chinese adolescents. Advances in Applied Sociology, 3(3), 178-85.

Ghazanfari, A. (2004). Validation and standardization of Identity Style Inventory (ISI-6G). Studies in Education and Psychology, 5(1), 1-8. 
Giddens, A. (2006). Sociology [H. Chavoshian (Persian trans.)]. Tehran: Ney Publication.

Green, M. F., Oliver, B., Crawley, J. N., Penn, D. L., \& Silverstein, S. (2005). Social cognition in schizophrenia: recommendations from the measurement and treatment research to improve cognition in Schizophrenia new approaches conference. Schizophrenia Bulletin, 31(4), 882-87.

Hyun Lee, B. (2009). The impact of parental monitoring on delinquent behaviors. Michigan: Michigan State University.

Khademi, A. (2010). [Modern Approaches to Psychology of Criminal Behavior (Persian)]. Tehran: Alam Publication.

Mikaeili, F. (2008). [The Relationship between identity styles, identity commitment and gender and compatibility of students at University (Persian)]. Journal of Psychological Studies, 6(2), 23-31.

Navah, A. R., \& Kouhpaie, M. B. (2012). [Social and personality factors affecting the tendency toward vandalism among high school students in Ahvaz (Persian)]. Iranian Journal of Social Development Studies, 4(2), 131-43.

Pouryousefi, H., Tayefeh, A., \& Aghapour, M. (2009). [A sociological study of the factors affecting social behavior modelling in girls (Persian)]. Journal of Social Sciences Research, 3(1), 159-92.

Sa'adat, S., \& Khodayari Saghavaz, H. (2012). A Study of the Relationship between Coping Strategies and Tendency to Delinquency. Paper presented at National Conference on Crime and Social Problems, Mazandaran, Iran, 27 February 2012.

Schug, R. A., Andrea, L., Glenn, M, P., Yaling, Y., \& Adrian, R. (2010). The Developmental Evidence Base: Neurobiological Research and Forensic applications. In G. J. Towl \& D. A. Crighton (Eds.), A Textbook of Forensic Psychology (pp. 73-87). Oxford: Blackwell.

Schultz, D. P., \& Schultz, S. E. (2005). Theories of Personality [Y. Seyed Mohammadi (Persian trans.)]. Tehran: Virayesh Publication.

Zare Shirinkand, D. (2013). [A Study of the Relationship between Social Disorganization and Social Learning of Delinquency among Adolescents in Tehran (Persian)] (MA thesis). Tehran: University of Social Welfare and Rehabilitation Sciences. 